\title{
Nanoparticles for fingermark detection: an insight into the reaction mechanism
}

\author{
S Moret*, A Bécue and C Champod
}

Institut de Police Scientifique, Ecole des Sciences Criminelles, Batochime, University of Lausanne, CH-1015 Lausanne, Switzerland

\section{Corresponding Author}

Dr. Sébastien Moret

Institut de Police Scientifique

Ecole des Sciences Criminelles

Building Batochime

University of Lausanne

CH-1015 Lausanne

Switzerland

Phone: 0041216924630

E-Mail address: sebastien.moret.3@unil.ch 
Abstract. This publication presents one of the first use of silicon oxide nanoparticles to detect fingermarks. The study is not confined to showing successful detection of fingermarks but is focused on understanding the mechanisms involved in the fingermark detection process. To gain such an understanding, various chemical groups are grafted onto the nanoparticles surface, and parameters such as the $\mathrm{pH}$ of the solutions or zeta potential are varied to study their influence on the detection. An electrostatic interaction was the generally accepted hypothesis of interaction between nanoparticles and fingermarks, but the results of this research challenges that hypothesis, showing that the interaction is chemically driven. Carboxyl groups grafted onto the nanoparticles surfaces react with amine groups of the fingermark secretion. This formation of amide linkage between carboxyl and amine groups has further been favoured by catalysing the reaction with a compound of diimide type. The research strategy adopted here ought to be applicable to all detection techniques using nanoparticles. For most of them the nature of the interaction remains poorly understood.

Keywords. Forensic science, fingermark detection, detection mechanism, silicon oxide, electrostatic interaction, chemical reaction, luminescence.

Submitted to. Nanotechnology 


\section{Introduction}

Following the same trend affecting most scientific and technical disciplines, nanotechnology has also an impact on forensic science. This is especially true for the detection of fingermarks on potentially touched items for which researchers have been very active for more than a decade [1-3] motivated by the fact that a substantial number of fingermarks (estimated to $50 \%$ on porous surfaces [4]) remains undetected.

Before that trend in nanoparticles research, numerous detection techniques have been developed to target the various components of the fingermark residue (e.g. amino acids [5] or lipids [6]). However, there still exists a lack of sensitivity and selectivity (ability to target specific component of the residue aside from the underlying substrate [7]). Nanoparticles (NPs) are then proposed as a way to tackle these issues. Their low size, their versatility and the ability to specifically tune their surface properties are the main reasons why they attract so much attention [8]. The surface modification versatility of these materials may lead to precise targeting of compounds present in the residue [9], and thus increasing the selectivity [10]. Their various optical properties can lower the detection limits, and improve the sensitivity, typically by using luminescent properties to get rid of background interference.

Many types of NPs have been investigated in this context: metal oxide [2], gold [11], silver [12], silicon oxide [13] and semiconductors (such as quantum dots [14]) to cite a few. These NPs can be applied either as dried powders or in suspension (aqueous or organic solvent) by immersion of the item. Powdering mostly relies on physical processes. For example, oleylamine-stabilized gold NPs powdered on fingermarks led to successful detection due to the affinity of the aliphatic functionalized NPs with the fingermark residue (sweat, sebum or other contaminants) [15]. This application suffers from a lack of selectivity as well as major health and safety issues. The use of a suspension however promotes physico-chemical and chemical interactions with the residue. For example, successes have been obtained with gold NPs functionalized with aliphatic chains and suspended in petroleum ether [16], or with gold colloids surrounded by citrate ions in aqueous solution [17].

However very few is known about the precise mechanisms involved in the interaction between the NPs and the fingermark residue. One cause for the paucity of research is the complexity of the residue 
which is composed in part from sweat produced by eccrine glands $(98 \%$ of water, amino acids, proteins, glucose, urea and inorganic ions), fatty compounds excreted by the sebaceous glands (e.g. fatty acids, wax esters, squalene) and contaminants (e.g. cosmetics, dirt or blood) [18, 19]. Besides the complexity of the residue, in situ studies of fingermarks are strongly limited due to the low quantity of material, the low thickness of material and the overall fragility of the secretion residue. Another reason can be found in the research strategies that are focused on the premature application of NPs (often in the form of powder) rather than on the study of fundamental principles involved in the detection process. This leads to publications of techniques supported by empirical optimizations, only, with considerable variations from one publication to the other even for the same type of NPs. An example is the use of cadmium telluride quantum dots (CdTe QDs), for which two papers describe opposite detection conditions $[14,20]$. The results obtained so far with NPs are consequently not optimal.

The present work aims at proposing a better understanding of the interactions occurring between NPs and fingermarks. To achieve that objective this research focused on one existing technique - the multimetal deposition (MMD) [21] - based on gold NPs in aqueous solution and for which a suggested mechanism based on electrostatic interaction is commonly accepted [10]. The MMD relies on a two-steps process. First, gold NPs of a size ranging from 14 to $30 \mathrm{~nm}$ are attracted on secretion at acidic $\mathrm{pH}$. Second, a selective reduction of silver [17] or gold [22] on the deposited NPs allows to enhance the contrast, and by the same way leads to the fingermark visualization.

The initial deposition of gold NPs on the fingerprint residue is known to be sensitive to the $\mathrm{pH}$ of the colloidal gold solution, with a very narrow effective $\mathrm{pH}$ range (around 3). The commonly accepted theory states that at acidic $\mathrm{pH}$ range, secretions are positively charged due to the protonation of amine groups (amino acids, proteins). NPs are in turn negatively charged due to citrate ions adsorbed on their surfaces. Colloids are then attracted onto secretions, allowing fingermarks to be detected [11, 23, 24] (figure 1). The narrow $\mathrm{pH}$ range is a best-so-far equilibrium between negatively charged NPs and positively charged fingermarks. Although this hypothesis is widely accepted, it has never been demonstrated. 

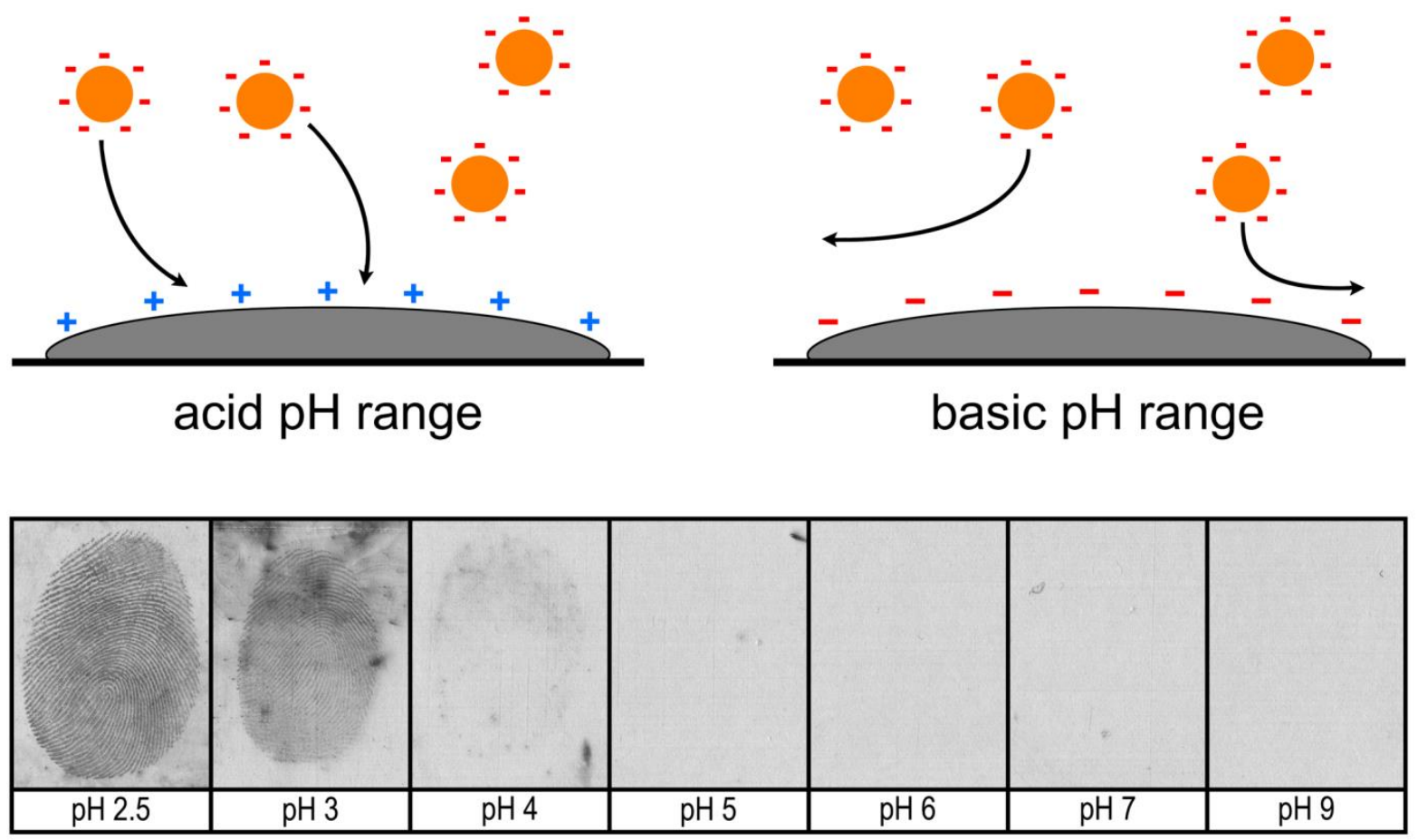

Figure 1. Schematic illustration of the electrostatic interaction hypothesis. At acid $\mathrm{pH}$, NPs (negatively charged) are attracted onto fingermark secretions (positively charged). At basic $\mathrm{pH}$, both NPs and fingermark residues are negatively charged, hindering the detection, as illustrated experimentally.

Silicon oxide NPs $\left(\mathrm{SiO}_{2} \mathrm{NPs}\right)$ were preferred to gold nanoparticles to explore the underpinning mechanisms. Contrary to gold $\mathrm{NPs}, \mathrm{SiO}_{2} \mathrm{NPs}$ offer versatile surface modification abilities combined with extended optical properties (e.g. by introducing a dye in their inner structure) $[13,25,26] . \mathrm{SiO}_{2}$ NPs can thus be used as a tool to systematically investigate the interactions occurring with the fingermarks.

\section{Experimental methods}

\subsection{Synthesis of functionalized silicon oxide nanoparticles and characterization}

Tetraethyl orthosilicate (TEOS), Triton X-100 (TX-100), cyclohexane, n-hexanol, ammonium hydroxide $\left(25\right.$ wt \%), rhodamine $6 \mathrm{G}$, sodium chloride $(\mathrm{NaCl}), N$-ethyl- $N N^{\prime}$-(3-dimethylaminopropyl) carbodiimide hydrochloride (EDC), N-hydroxysuccinimide (NHS), propionic acid and 3(trihydroxysilyl)propyl methylphosphonate monosodium salt solution were purchased from Sigma- 
Aldrich. Carboxyethylsilanetriol sodium salt, 3-(trihydroxysilyl)-1-propanesulphonic acid and 3(triethoxysilyl)-propylsuccinic anhydride were purchased from Abcr $\mathrm{GmbH} \&$ Co. All chemicals were used as received without further purification.

$\mathrm{SiO}_{2} \mathrm{NPs}$ were synthesized by the microemulsion method described by Wang et al. [27]. The protocol was followed without any modifications, except the incorporation of the dye: dual rare earth luminophores were replaced by rhodamine 6G. The water-in-oil microemulsion was obtained by successively mixing $3.54 \mathrm{~mL}$ of TX-100, $15 \mathrm{~mL}$ of cyclohexane, $3.6 \mathrm{~mL}$ of $\mathrm{n}$-hexanol and $960 \mu \mathrm{L}$ of a 0.1 M rhodamine 6G. After stabilization of the micro-emulsion, NPs formation was initiated by adding $200 \mu \mathrm{L}$ of TEOS, followed by $120 \mu \mathrm{L}$ of ammonium hydroxide. The mixture was kept under stirring for $24 \mathrm{~h}$.

The prepared $\mathrm{SiO}_{2}$ NPs were functionalized directly in the micro-emulsion. $50 \mu$ of TEOS and 170 $\mu \mathrm{mol}$ of the selected silane coupling agent were added to the mixture. After another $24 \mathrm{~h}$, a large excess of ethanol was added to destabilize the system. NPs were collected by centrifugation ( 3500 $\mathrm{RCF}$ for 10 minutes) and washed twice with ethanol and then re-dispersed in $20 \mathrm{~mL}$ of RO/DI water $(18.2 \Omega \cdot \mathrm{cm})$.

NPs hydrodynamic diameter was measured by dynamic light scattering (DLS) and zeta potential $(\zeta)$ was determined by laser Doppler micro-electrophoresis, both on a Zetasizer Nano ZS (Malvern Instruments Ltd.). For each sample, the hydrodynamic diameter was measured five times while the $\zeta$ was measured three times. In both cases, average data were used. To determine the behaviour of the $\mathrm{SiO}_{2} \mathrm{NPs}$ over $\mathrm{pH}$ range, $\mathrm{pH}$ was adjusted by adding $\mathrm{NaOH}$ or $\mathrm{HCl}$ to the solutions. Each obtained values was then plotted showing both hydrodynamic diameter and $\zeta$ evolutions.

Photoluminescence properties of the NPs solutions were measured at room temperature on a Hitachi F-2500 fluorescence spectrometer. All measurements were made on samples obtained after redispersion of the $\mathrm{SiO}_{2} \mathrm{NPs}$ in water.

\subsection{Fingermark deposition}


The study is specifically designed to better understand fundamental principles of the interaction between NPs and fingermarks. Therefore only one substrate and one donor were chosen. Aluminum foil has been selected as an ideal substrate. A donor known as "good" was selected in order to have a sufficient amount of natural secretions. Fingermarks were deposited on aluminum foils following a standard procedure consisting in successive apposition of the right thumb, index, middle and ring finger. These marks were considered as naturally mixed, containing both eccrine and sebaceous secretions. The only restriction was that the donor has not washed his hands at least one hour before deposition and behaved normally in the meanwhile. To prevent deposition of overloaded marks, the donor was not asked to rub his fingers on his face before deposition, but only to rub his hands together in order to homogenize the already-present secretions. The fingermarks samples were finally stored in dark for at least three weeks before being processed. The delay between the fingermark deposition and the treatment of samples was critical. The three-week delay was chosen in order to avoid a "fresh mark effect", giving misleading or not representative results.

\subsection{Fingermark detection and recording}

Before processing, the $\mathrm{SiO}_{2}$ NPs solutions were diluted by two with $\mathrm{RO} / \mathrm{DI}$ water and the $\mathrm{pH}$ was adjusted with either $\mathrm{NaOH}$ or $\mathrm{HCl}$ solutions, depending on the desired $\mathrm{pH}$ range. The solution was then poured in a dish. The amount of solution must be sufficient to cover the bottom of the dish. The samples were deposited on the surface of the solution with fingermarks facing down and then let float for one hour without stirring. After treatment, the aluminum foils were rinsed in deionized water to wash away the non-bounded NPs.

For the detection solution containing EDC/NHS, the detection conditions have been optimized with a pH set at 6. The $\mathrm{SiO}_{2}$ NPs solutions were diluted by four with $\mathrm{RO} / \mathrm{DI}$ water and the immersion time reduced to 30 minutes.

Once dry, the samples were observed in luminescence mode, i.e. with an excitation at $495 \mathrm{~nm}$ and an observation filter with a band pass centred at $590 \mathrm{~nm}$. Each result was recorded under the same illumination conditions and with the same camera settings. No other specific digital enhancements were performed. 


\section{Results and discussion}

Silicon oxide nanoparticles $\left(\mathrm{SiO}_{2} \mathrm{NPs}\right)$ were synthesized by reverse microemulsion method, allowing to graft chosen functional groups onto the NPs surface [28-30]. An organic dye, rhodamine 6G, was introduced within the structure to provide luminescent properties to NPs. Excitation and emission spectra of the doped $\mathrm{SiO}_{2}$ are shown in figure 2. Dynamic light scattering (DLS) was used to characterize the obtained NPs (such as hydrodynamic diameter and zeta potential intensity). An average diameter of $70 \mathrm{~nm} \pm 2 \mathrm{~nm}$ was obtained.

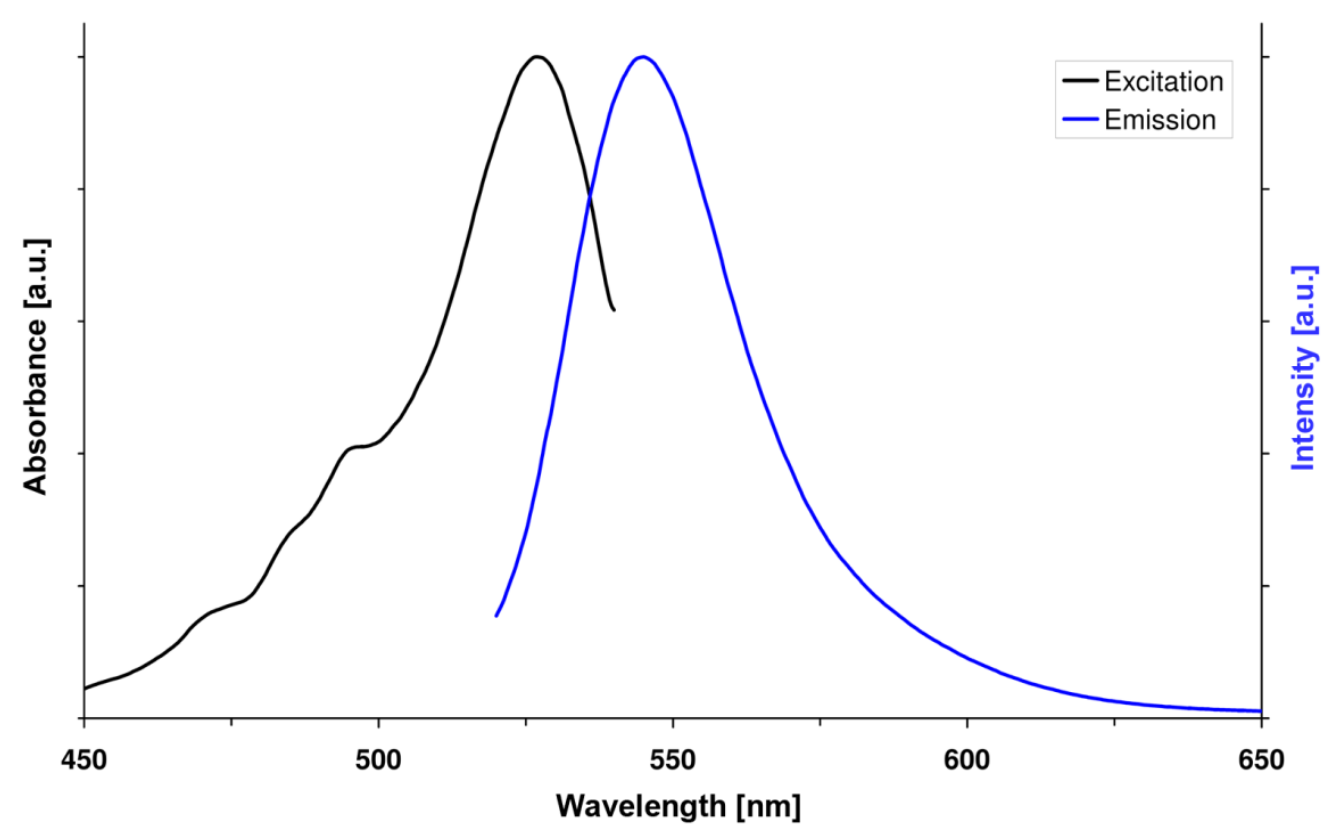

Figure 2. Excitation and emission spectra of a silicon oxide nanoparticles aqueous solution, doped with rhodamine $6 \mathrm{G}$.

Detailed synthetic procedures, fingermarks collect and storage, as well as detection protocols and fingermarks recording are available in the "Experimental Methods" section.

\subsection{Implementing the electrostatic interaction}

As a starting point, $\mathrm{SiO}_{2}$ NPs are used to mimic the physico-chemical properties of the gold NPs used for MMD. Since a major property of gold colloids is the negative charge due to the adsorbed sodium citrate - bearing three carboxyl groups, carboxyethylsilanetriol has been chosen as silane 
coupling agent. This molecule possesses a carboxyl group, which provides a negative charge to NPs in alkaline solution. If the detection mechanism is effectively driven by electrostatic attraction, the carboxyl-functionalized $\mathrm{SiO}_{2} \mathrm{NPs}\left(\mathrm{SiO}_{2}-\mathrm{COOH}\right)$ are expected to reproduce the affinity of gold $\mathrm{NPs}$ for fingermarks at acidic $\mathrm{pH}$.

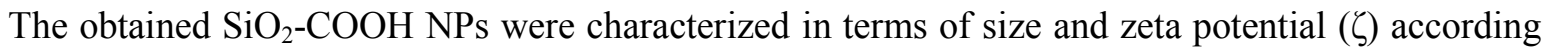
to the $\mathrm{pH}$ (figure 3). The measured hydrodynamic diameter, of about $70 \mathrm{~nm}$, remains constant along the $\mathrm{pH}$ range. No aggregate formation is detected. Regarding $\zeta$, the value is negative over the entire $\mathrm{pH}$ range, as expected. Above $\mathrm{pH} 4$, the particles possess a strong negative $\zeta(<-30 \mathrm{mV})$, which gives a good stability to the solution [31]. Below $\mathrm{pH} 4$, the $\zeta$ potential increases rapidly to reach a value of zero at about $\mathrm{pH} 1$. This is explained by the protonation of the carboxylic groups.

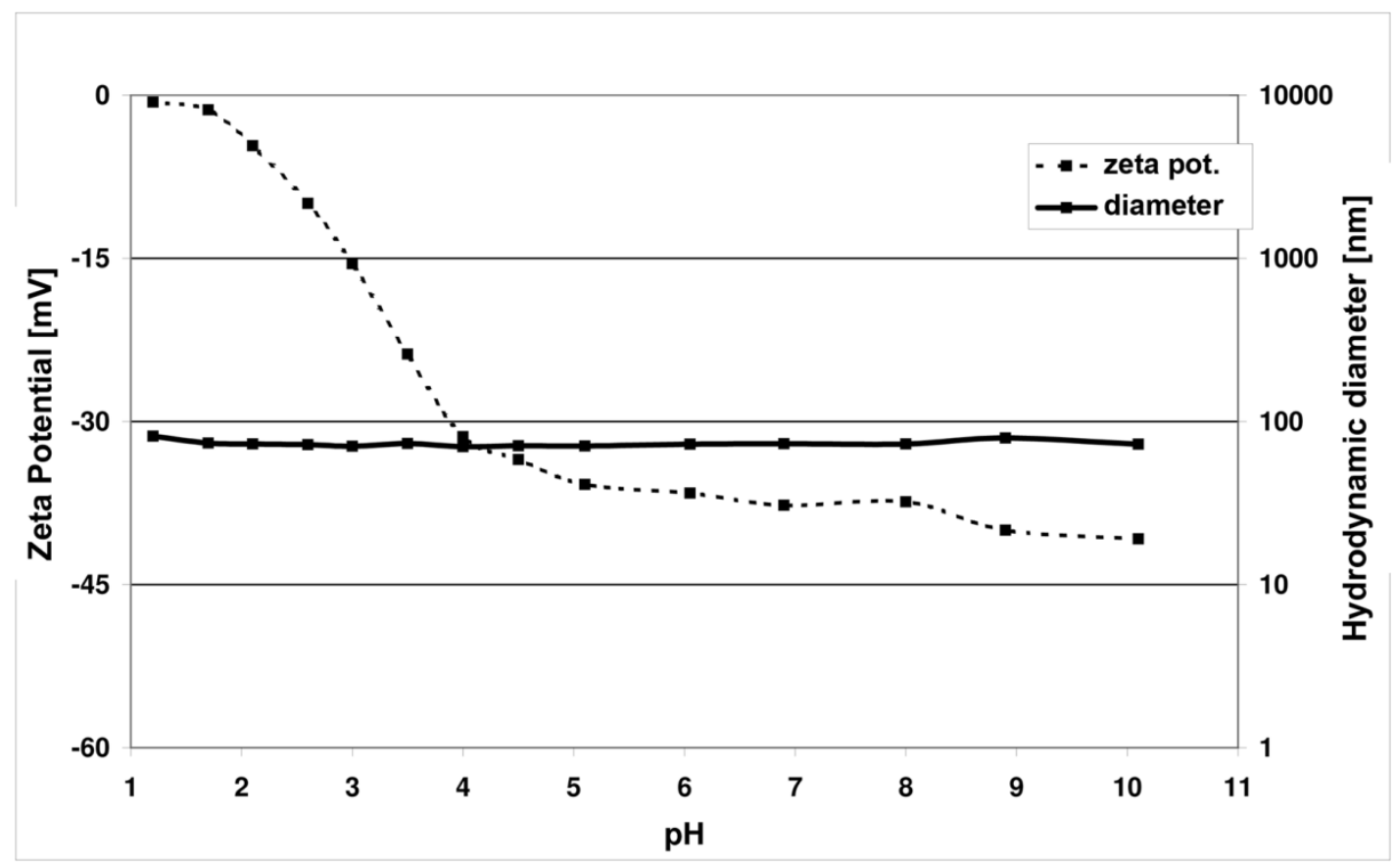

Figure 3. Graph showing the $\mathrm{pH}-d$ dependent evolution of both hydrodynamic diameter and zeta potential of an aqueous solution of $\mathrm{SiO}_{2} \mathrm{NPs}$ functionalized with carboxyl groups.

Figure 4 shows the results of fingermark detection with $\mathrm{SiO}_{2}-\mathrm{COOH}$ NPs solutions, along the 1.5 to $9 \mathrm{pH}$ range. The fingermarks have been cut in half and processed separately in order to compare the results that can be obtained upon these different parameters. The results are similar to those obtained using gold NPs (figure 1). According to the electrostatic interaction hypothesis, in the $\mathrm{pH} 5$ to 9 range both the secretions and the NPs possess a negative charge which induces a repulsion that hinders the 
detection. On the contrary, at $\mathrm{pH} 3$ the secretions are assumed to be positively charged, while NPs still possess a negative $\zeta$ of approximately $-15 \mathrm{mV}$. The attraction may thus take place, and marks are detected. At $\mathrm{pH} 1.5$, the $\zeta$ of the NPs is close to zero, whereas the papillary secretions are theoretically more strongly positively charged. The NPs are still attracted onto fingermarks, leading to their visualization.

These observations support at this stage the electrostatic hypothesis. If truly this interaction is driven by a compromise between the charges of different entities, it should then be possible to maximize this interaction - and thereby improve the quality of results - by using NPs presenting a strongly negative $\zeta$ at $\mathrm{pH} 3$.

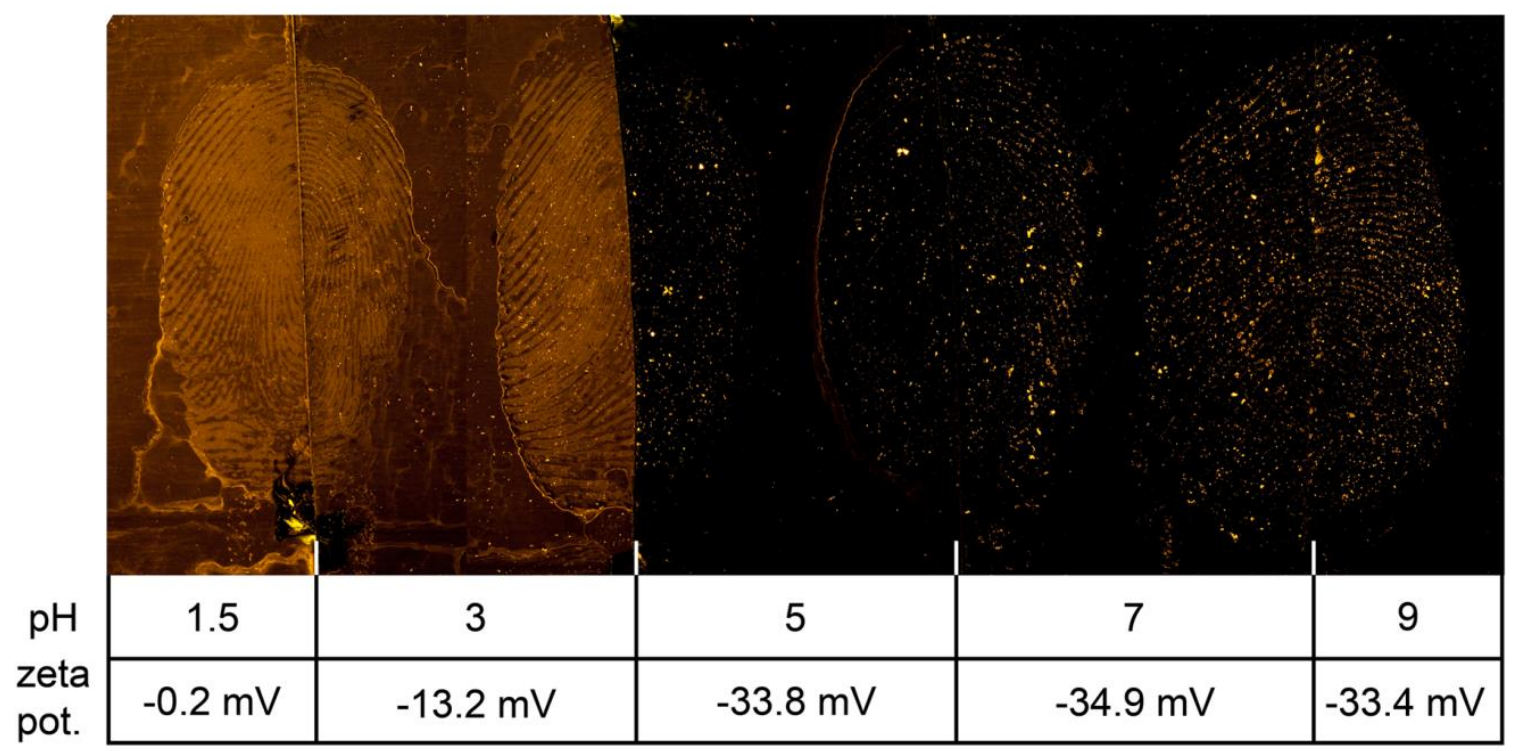

Figure 4. Results obtained after application of $\mathrm{SiO}_{2} \mathrm{NPs}$ functionalized with carboxyl groups, at various $\mathrm{pH}$, on fingermarks deposited on aluminum foils. For values of 5, 7 and 9, no results are visible, whereas for 1.5 and 3 , marks are detected.

\subsection{Attempts to maximize the electrostatic interaction}

In order to obtain NPs with a stronger $\zeta$ at lower $\mathrm{pH}$, succinic anhydride functions have been grafted around the $\mathrm{SiO}_{2} \mathrm{NPs}\left(\mathrm{SiO}_{2}-(\mathrm{COOH})_{2}\right)$. This functional group is hydrolysed in contact with water and forms two carboxylic groups. DLS analysis shows the physico-chemical properties of these NPs, following the same trend as $\mathrm{SiO}_{2}-\mathrm{COOH}$ (figure 5). 


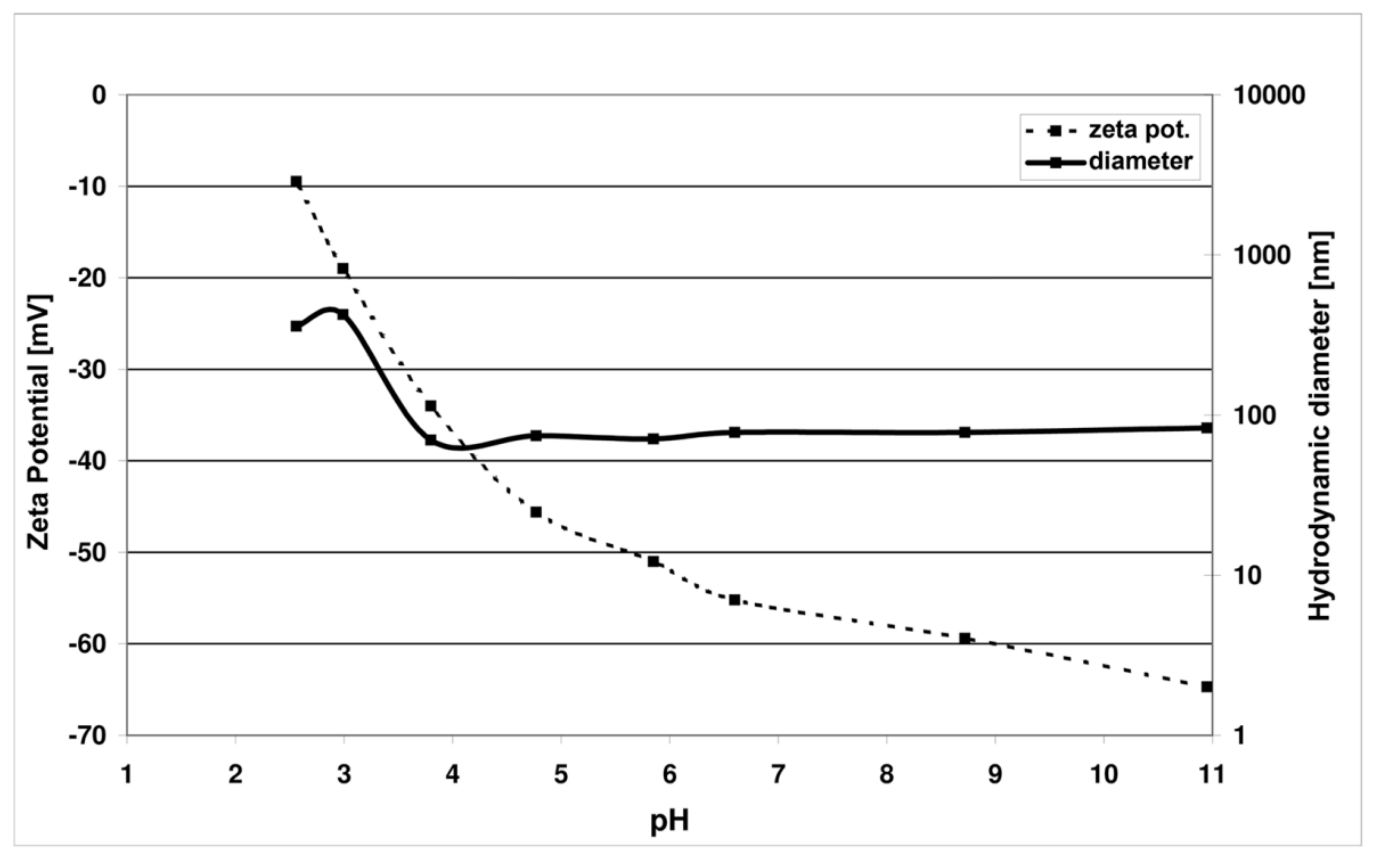

Figure 5. Graph showing the $\mathrm{pH}-$ dependent evolution of both hydrodynamic diameter and zeta potential of an aqueous solution of $\mathrm{SiO}_{2} \mathrm{NPs}$ functionalized with anhydride succinic groups.

When applied to fingermarks, these NPs behave similarly to the ones bearing a single carboxyl group (figure 6). Above $\mathrm{pH} 5$, no detection occurs. At pH 3.5, luminescent fingermarks are obtained. The $\zeta$ has a value of $-26 \mathrm{mV}$, which is about 10 units more negative than the $\zeta$ value measured at $\mathrm{pH} 3$ with $\mathrm{SiO}_{2}-\mathrm{COOH}$ NPs $(-13.2 \mathrm{mV})$. The last result obtained at $\mathrm{pH} 2.8$ cannot be taken into consideration since at this value the solution was not stable and NPs started to aggregate. Therefore, values of $\mathrm{pH}$ below 3.5 are not suitable to detect fingermarks with these NPs.

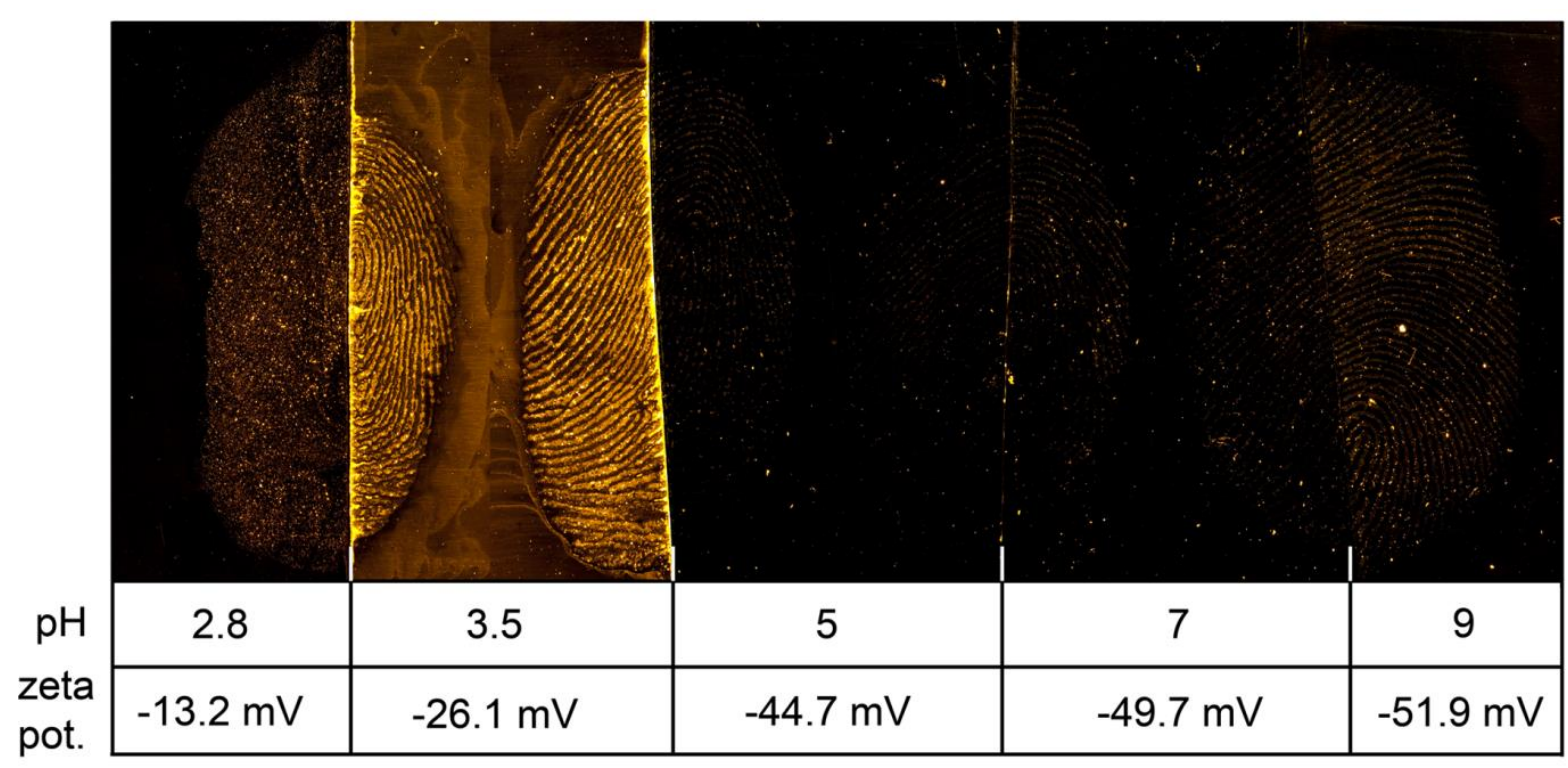


Figure 6. Results obtained after application of $\mathrm{SiO}_{2} \mathrm{NPs}$ functionalized with anhydride succinic groups, at various $\mathrm{pH}$, on fingermarks deposited on aluminum foils. For values of 5, 7 and 9, no results are visible. At $\mathrm{pH} 3.5$, marks are detected. At $\mathrm{pH} 2.8$, blurred and weakly luminescent marks are obtained due to NPs instability and aggregate formation.

Two other alternatives to carboxyl groups are methylphosphonate $\left(-\mathrm{OP}(\mathrm{O})(\mathrm{ONa}) \mathrm{CH}_{3}\right)$ and sulfonate $\left(-\mathrm{SO}_{3} \mathrm{H}\right)$ groups. DLS analyses of these two different functionalized NPs show that both solutions are stable and possess a highly negative $\zeta$ on the entire $\mathrm{pH}$ range (figure 7 ). Figure 8 shows samples treated with these two solutions of strongly-negatively-charged NPs, respectively functionalized with (a) methylphosphonate groups, and (b) sulfonate groups. Unlike the previous results obtained with $\mathrm{SiO}_{2}-\mathrm{COOH}$ and $\mathrm{SiO}_{2}-(\mathrm{COOH})_{2}$, which allow to detect marks at $\mathrm{pH} 3$, these highly charged NPs have absolutely no affinity with the fingermark residue, regardless of the $\mathrm{pH}$ value.

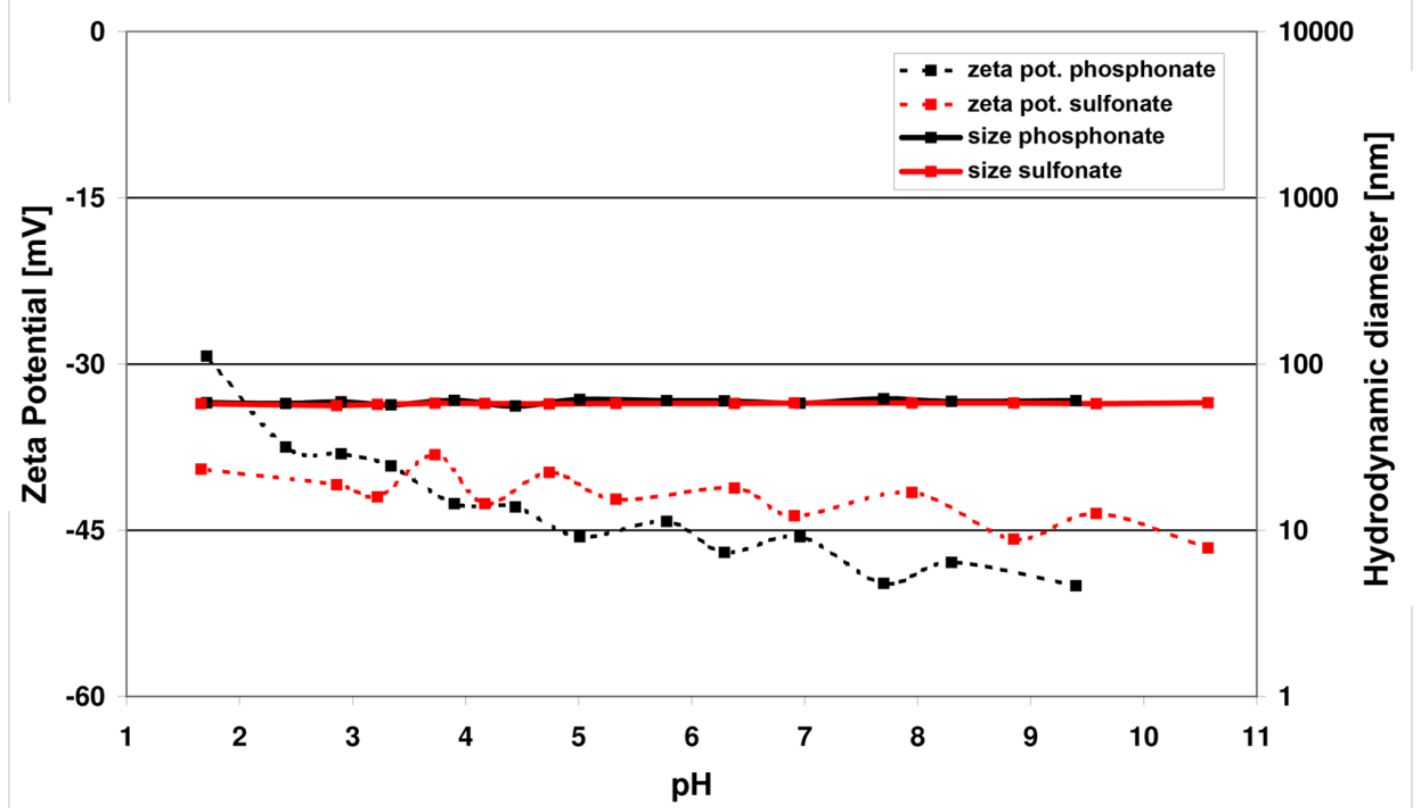

Figure 7. Graph showing the $\mathrm{pH}-d e p e n d e n t ~ e v o l u t i o n$ of both hydrodynamic diameter and zeta potential of two aqueous solutions of $\mathrm{SiO}_{2} \mathrm{NPs}$ functionalized respectively with phosphonate and sulfonate groups. 


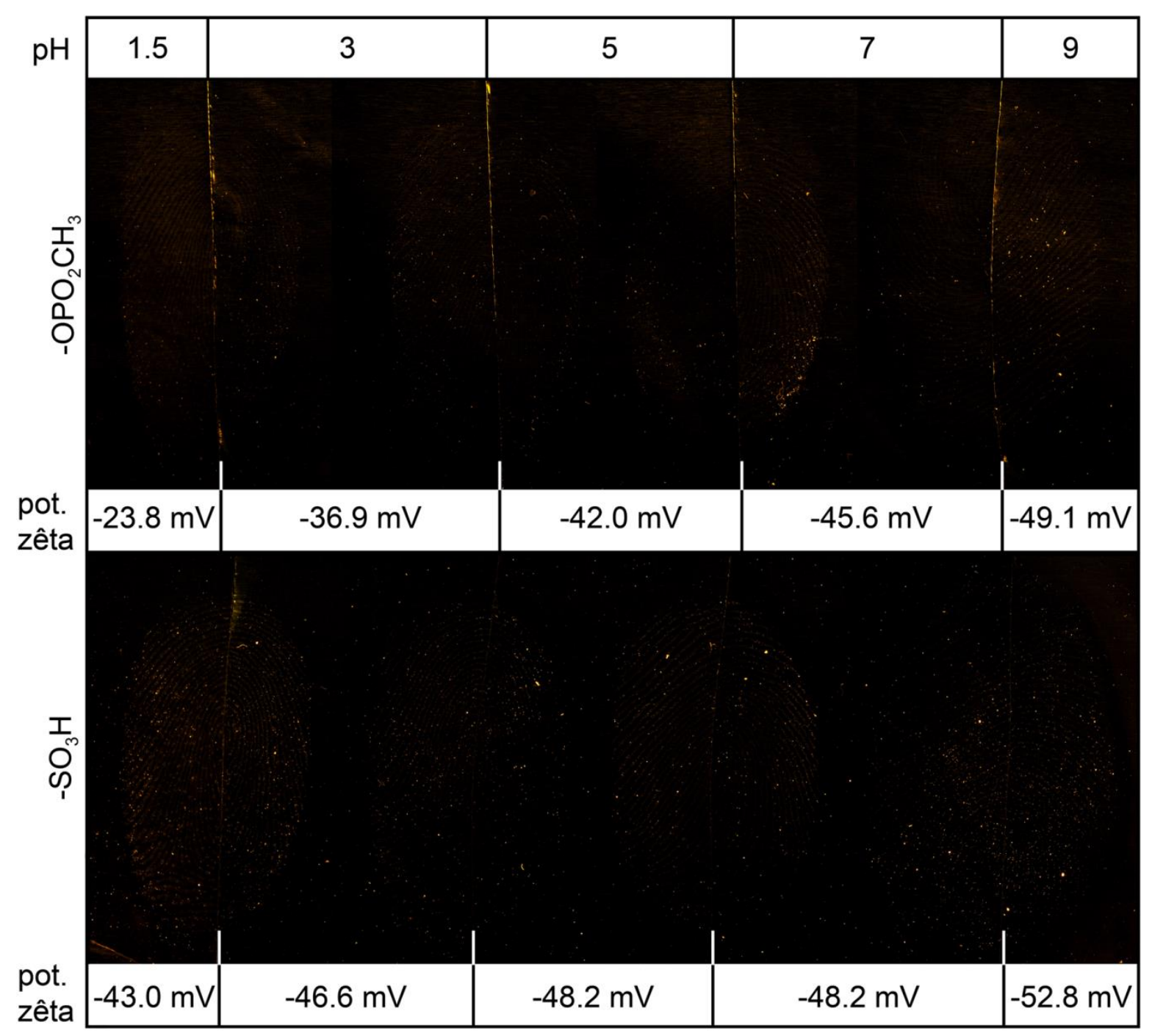

Figure 8. Results obtained after application at various $\mathrm{pH}$ of $\mathrm{SiO}_{2} \mathrm{NPs}$ functionalized with phosphonate groups (above) and sulfonate groups (below), on fingermarks deposited on aluminum foils. No marks are detected regardless the value of the $\mathrm{pH}$.

These results undermine the electrostatic interaction hypothesis. Indeed four types of NPs solutions sharing similar properties such as size and concentration have been applied onto fingermark samples. The detection conditions (immersion time, $\mathrm{pH}$ ) and fingermark samples (donor, age of the marks, substrate and storage) were kept unchanged between the sets of detection. Only two parameters may have led to this absence of results: $\zeta$ intensities and chemical groups grafted onto the NPs surface. This led us to formulate two additional hypotheses: (1) the electrostatic interaction drives the detection, but a too high $\zeta$ leads to a very stable solution, preventing the NPs from being deposited on the mark, (2) a chemical reaction between carboxyl functions and fingermark secretions enables the 
detection. A joint effect of both $\zeta$ and chemical groups may also be envisaged.

\subsection{Questioning the electrostatic hypothesis}

The above results indicate that detection occurs with $\mathrm{SiO}_{2}-\mathrm{COOH}$ and $\mathrm{SiO}_{2}-(\mathrm{COOH})_{2}$, with values of $\zeta$ ranging from $-25 \mathrm{mV}$ to $-15 \mathrm{mV}$. These values do not seem to affect the interaction between NPs and secretions. However, $\mathrm{pH}$ and $\zeta$ remain closely related parameters that should be studied separately, in order to isolate their respective impact on the detection mechanism. Another set of experiments consist of modifying the ionic strength of the solution by adding sodium chloride $(\mathrm{NaCl})$ to the NPs solution. The aim is to influence the $\zeta$ without altering the $\mathrm{pH}$ of the solution.

Measurements made on $\mathrm{SiO}_{2}-\mathrm{COOH}$ and $\mathrm{SiO}_{2}-\mathrm{SO}_{3} \mathrm{H}$ NPs solutions show that addition of $\mathrm{NaCl}$ lead to a decrease of $\zeta$ intensity proportional to the amount of $\mathrm{NaCl}$ added, but independently of the $\mathrm{pH}$ of the solution. The effect of $\zeta$ on fingermark detection ability is then studied. For both functionalizations, a solution without $\mathrm{NaCl}$ is also applied as for comparison purposes (figure 9). The results obtained with $\mathrm{SiO}_{2}-\mathrm{COOH}$ firstly indicate that the presence of $\mathrm{NaCl}$ in the solution does not hinder the detection of fingermarks (figure 9a), with successful mark detection even at low $\zeta$. However, the application of solutions containing $\mathrm{NaCl}$ led to marks of lower quality compared to those obtained with the solution without $\mathrm{NaCl}$. This is due to the fact that at $\mathrm{pH} 3$ and with such salt concentration, the $\zeta$ of the particles is close to zero and is therefore not sufficient to ensure a proper stability of the NPs in solution. When it comes to $\mathrm{SiO}_{2}-\mathrm{SO}_{3} \mathrm{H}$ NPs, even with low $\zeta$, no marks could be detected (or to a very limited extend in comparison to the results obtained with the carboxylic group) (figure $9 b$ ). These results clearly indicate that the $\zeta$ of NPs is not the main criterion influencing the interaction, hence confirming that electrostatic interaction is not so critical in the detection process. 


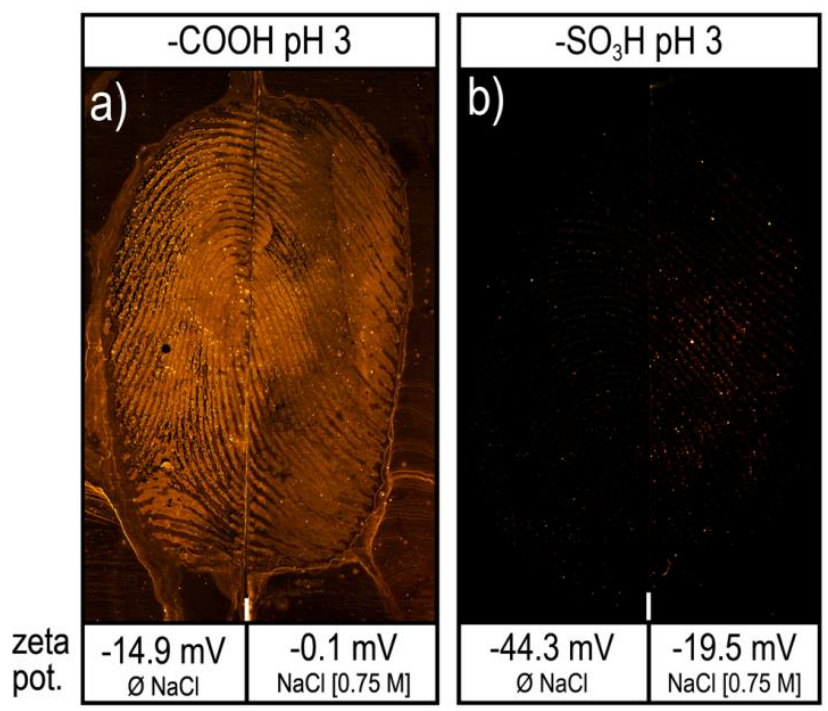

Figure 9. Results obtained after application of $\mathrm{SiO}_{2}$ NPs functionalized with: a) carboxyl groups, b) sulfonate groups, at $\mathrm{pH} 3$. Solutions containing sodium chloride $[0.75 \mathrm{M}]$ are applied on the right side of the marks.

To evaluate the influence of the $\mathrm{pH}, \mathrm{SiO}_{2}-\mathrm{COOH}$ NPs are applied at $\mathrm{pH} 9,7,5$ and 3, with and without $\mathrm{NaCl}$ in the solution (figure 10). These results provide another important element to the understanding of the underpinning mechanism. For a standard solution of $\mathrm{SiO}_{2}-\mathrm{COOH}$, detection of fingermarks occurs only if the $\mathrm{pH}$ is adjusted around 3 and if the $\zeta$ is located between -25 and $-15 \mathrm{mV}$. When $\mathrm{NaCl}$ is present in the solution, fingermarks can be detected at $\mathrm{pH}$ above 3 up to $\mathrm{pH}$ 7. Indeed, at $\mathrm{pH} 5$ and $7, \mathrm{NaCl}$ reduces the $\zeta$ at about $-20 \mathrm{mV}$. At $\mathrm{pH} 9, \zeta$ is also in the range of $-20 \mathrm{mV}$, but the detection obtained is not as satisfactory as the previous ones. This indicates that $\mathrm{pH}$ affects the detection mechanism but only to a limited extend. At basic $\mathrm{pH}$ range, for $\zeta$ of $-40 \mathrm{mV}$, the detection does not occur. Moreover, the assumption that fingermark residue is positively or negatively charged depending on the $\mathrm{pH}$ of the solution could not be verified here since negatively charged NPs interact with a supposed negatively charged fingermark at basic $\mathrm{pH}$ range. 

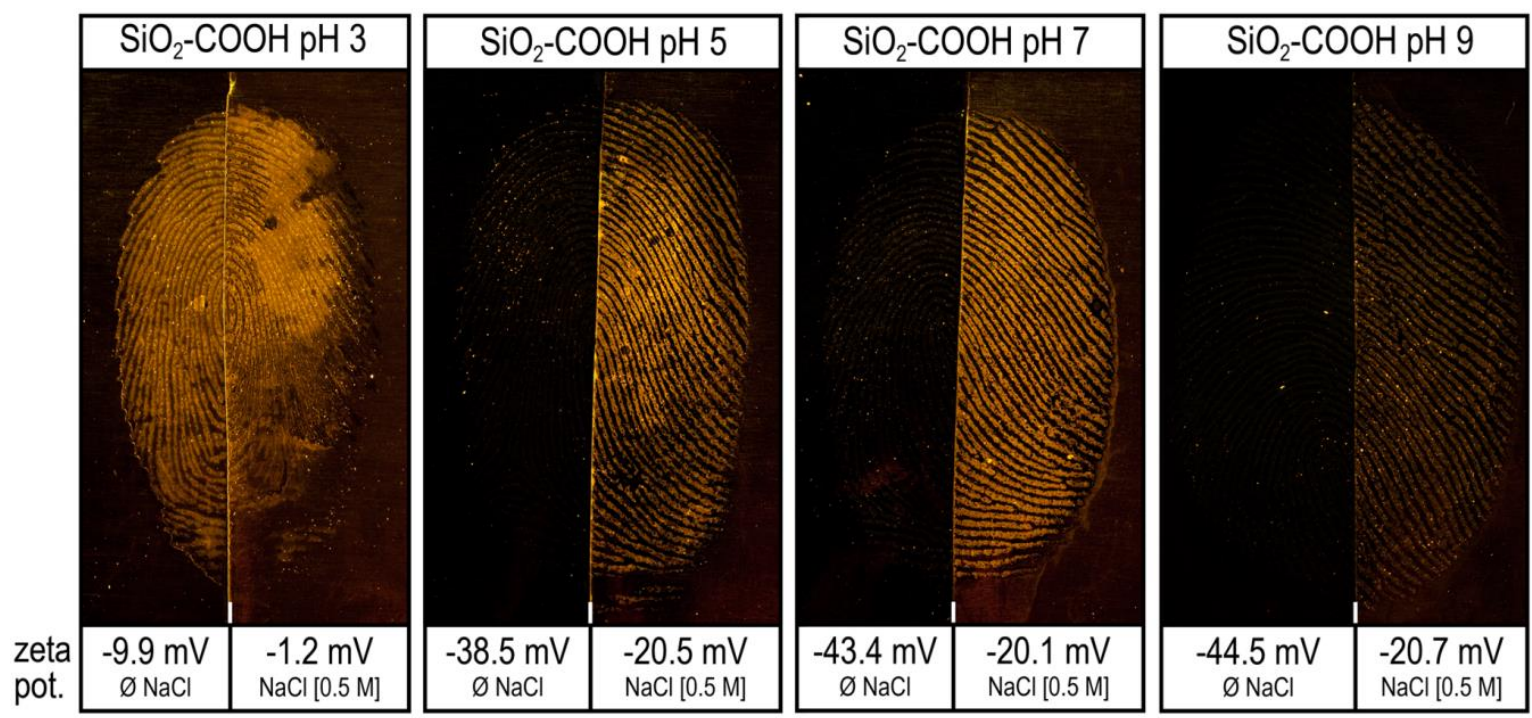

Figure 10. Results obtained after application of $\mathrm{SiO}_{2} \mathrm{NPs}$ functionalized with carboxyl groups, at pH varying from 3 to 9 . The fingermark samples are deposited on aluminum foil. The right half of the marks is treated with the solution containing sodium chloride $[0.5 \mathrm{M}]$.

It can be inferred from these results that an interaction between NPs and fingermarks occurs only when a carboxyl group is present on the NPs surface. No detection takes place in absence of these groups, regardless of the $\mathrm{pH}$. This goes in favour of a chemically driven detection process. However, $\zeta$ still remains a parameter to be taken into account. Indeed, even if carboxyl groups are present, too a high $\zeta$ hinders the detection by keeping the NPs in solution. The chemical interaction hypothesis is consequently explored further below.

\subsection{Exploring the chemical interaction hypothesis}

Results obtained so far indicate that carboxyl groups are involved in the detection process. They can reasonably be expected to form a peptide bond with the amine groups present in the secretions. This hypothesis is justified by the presence of both amine and carboxyl groups in the fingermark secretions (e.g. amino acids, proteins). If this bond is actually created, it may be possible to promote or accelerate its creation using a coupling agent. The most popular way to promote the formation of amide linkage between carboxyl and amine groups is by using carbodiimide groups ( $N$-ethyl- $N^{\prime}-(3-$ dimethylaminopropyl) carbodiimide hydrochloride - EDC) combined with N-hydroxysuccinimide (NHS) [32]. Together they activate carboxyl groups that will readily react with primary amines. 
Figure 11 illustrates a mark detected following immersion into a carboxyl-activated solution (right half) and a solution without EDC/NHS (left half), both at $\mathrm{pH}$ 6. For the same immersion time, the right half fingermark is detected with the activated NPs, while no counterpart is obtained in the absence of EDC/NHS.

To further verify that the reaction effectively occurs with activated carboxyl groups present on the surface of NPs, fingermarks have been immersed in three other solutions (all with EDC/NHS and at $\mathrm{pH}$ 6), respectively (1) without $\mathrm{SiO}_{2}$ NPs, (2) with non-functionalized NPs and (3) with methylphosphonate-functionalized NPs. The results illustrated in figure 12 show that the reaction takes place only when carboxyl groups are present in conjunction with EDC/NHS.
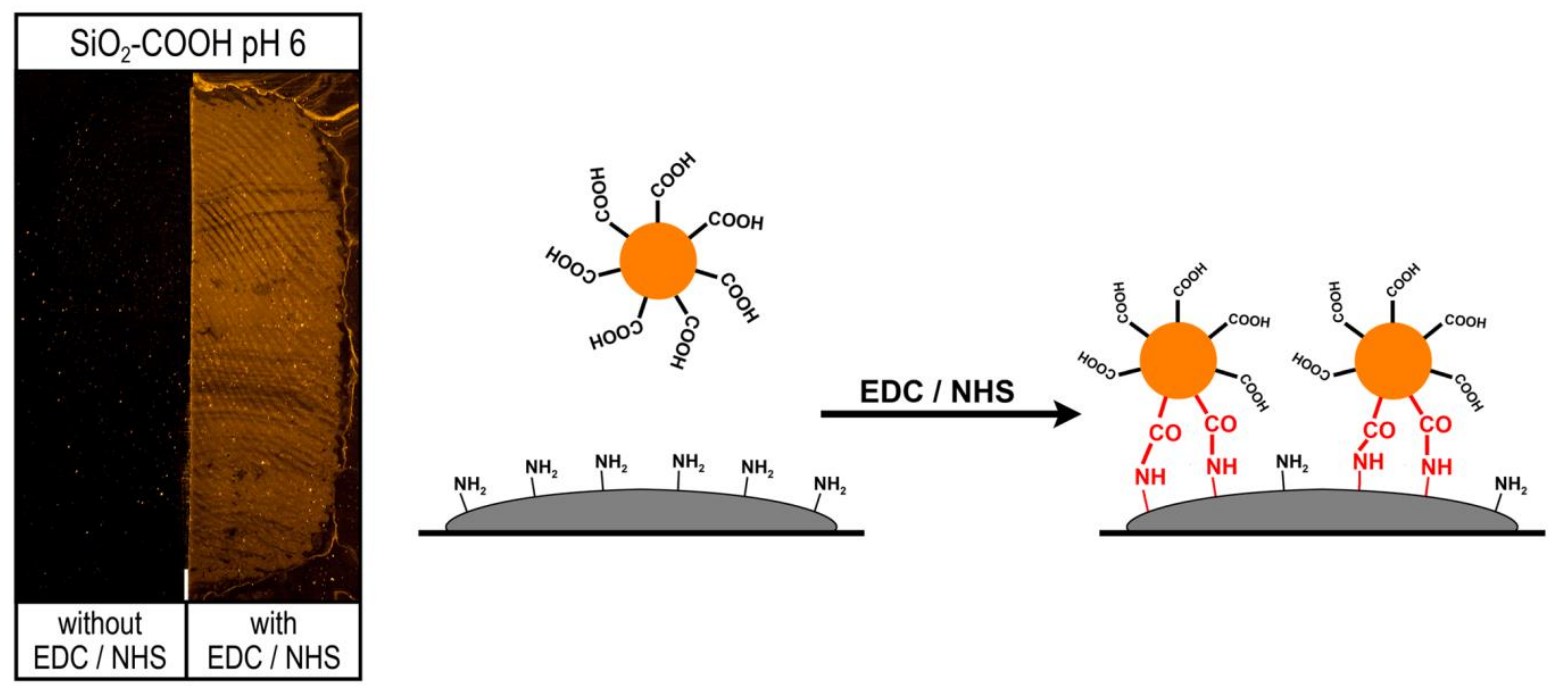

Figure 11. Results obtained after application of $\mathrm{SiO}_{2}-\mathrm{COOH} \mathrm{NPs}$ at $\mathrm{pH}$ 6. For the right half, EDC/NHS is used to mediate the reaction. On the right is a schematic illustration of the bond formation between carboxyl groups present on $\mathrm{SiO}_{2} \mathrm{NPs}$ surface and amine groups found in the fingermark secretion. The amide linkage is mediated by the use of EDC/NHS. 


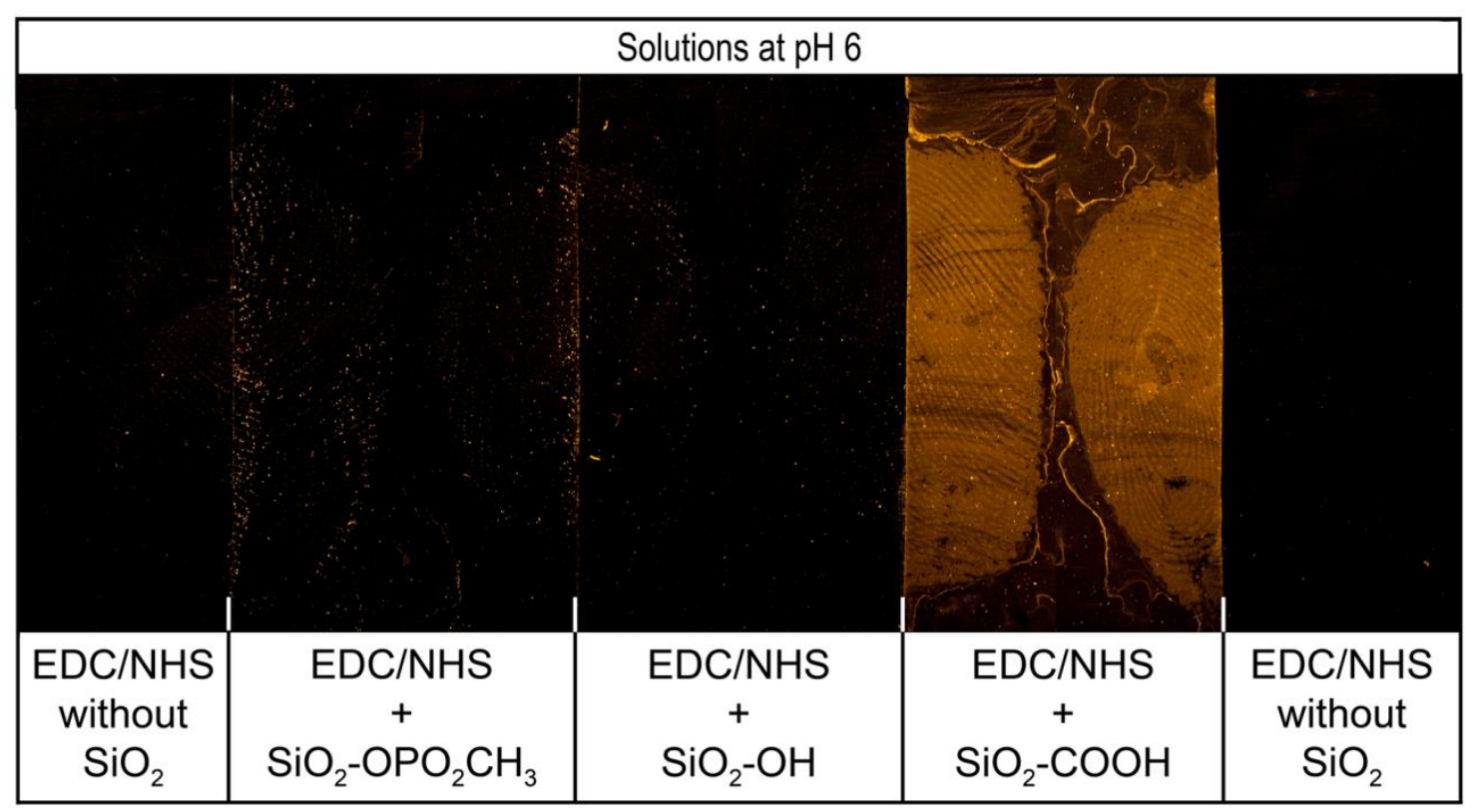

Figure 12. Illustration of the influence of the carboxyl groups at the NPs surface. Only solutions containing NPs functionalized with carboxyl groups are interacting with the marks.

Furthermore if the amine groups present in the residue are involved in the reaction process, it should be possible to hinder the bond formation by making them unavailable for the reaction with $\mathrm{SiO}_{2}-\mathrm{COOH}$ NPs. To do so, a propionic acid solution is activated using EDC/NHS and fingermarks are first immersed in this "amine-blocking" solution. Samples are then rinsed to remove the unreacted compounds, and immerged in a $\mathrm{SiO}_{2}-\mathrm{COOH}$ NPs solution at $\mathrm{pH}$. The image shown in figure 13 illustrates the effect of the "amine-blocking"; pretreated half fingermarks do not react with the $\mathrm{SiO}_{2}$ $\mathrm{COOH}$ NPs and the fingermark ridges are not detected, while non-blocked marks react normally. This result indicates that amine groups in the fingermark residue take effectively part in the detection process. 


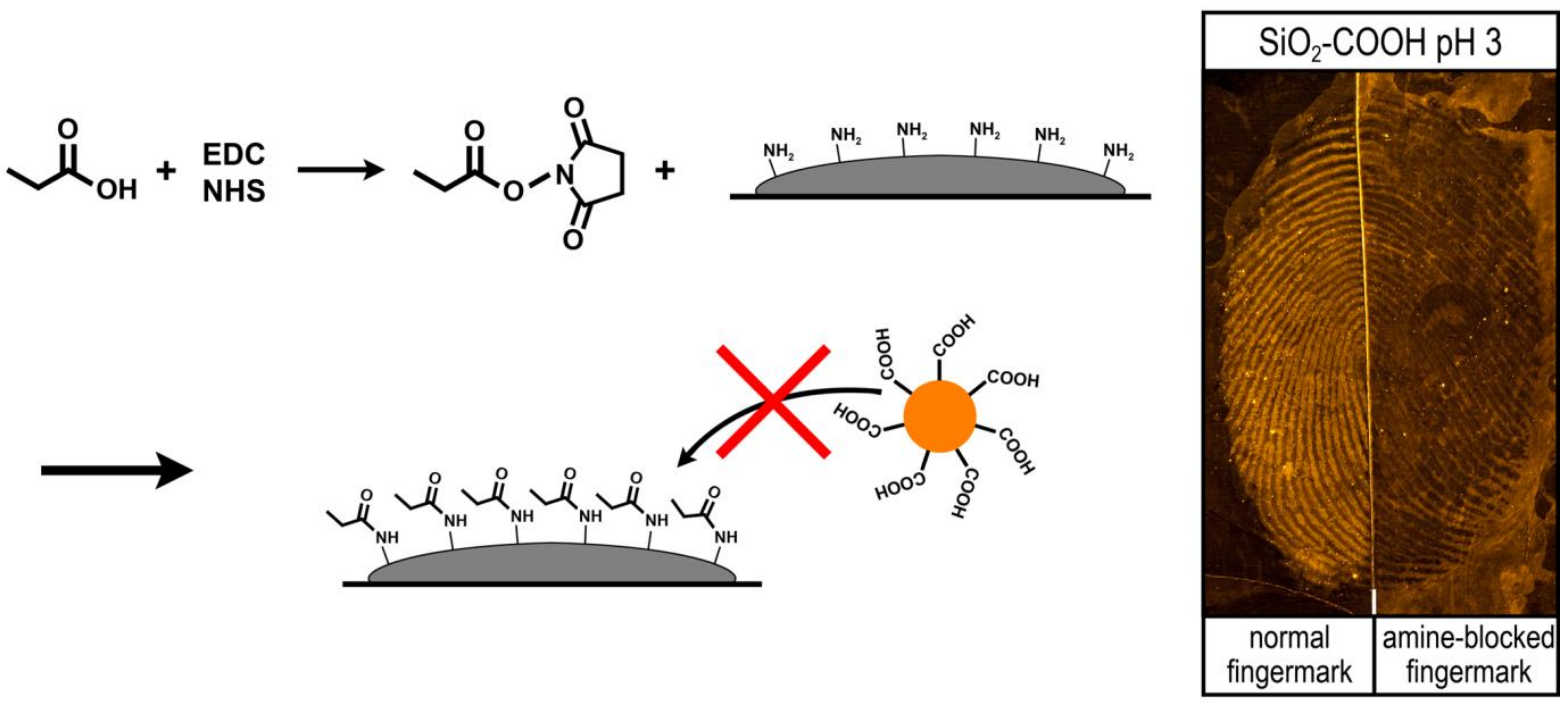

Figure 13. Result obtained after application of $\mathrm{SiO}_{2} \mathrm{NPs}$ on fingermarks deposited on aluminum foil, at $\mathrm{pH}$ 3. The right half has previously been treated with an "amine-blocking" solution. On the left is a schematic illustration of the "amine-blocking", which hinders the bond formation between carboxyl groups present on $\mathrm{SiO}_{2} \mathrm{NPs}$ surface and amine groups found in the fingermark secretion.

\section{Conclusion}

Functionalized silicon oxide nanoparticles $\left(\mathrm{SiO}_{2} \mathrm{NPs}\right)$ in aqueous solution have been used to study the mechanisms at play during the detection of fingermarks with the multimetal deposition technique (MMD, based on colloidal gold). The commonly accepted hypothesis for the detection mechanism is that of an electrostatic interaction, taking place in acidic conditions, between the negatively charged gold NPs and the positively charged fingermark residue. This paper provides evidence to refute that hypothesis and suggests a more probable path in the form of a chemical reaction between carboxylic groups of the NPs and the amines contained in fingermark residue.

These results provide new insights into the fundamental principles involved in fingermark detection using NPs. Such understanding gives promising routes to be applied to other detection techniques based on NPs such as the silver-based physical developer [33] which still relies on unverified hypotheses. 


\section{Author contribution}

The concept of the study and experimental design was agreed between all authors. The experimental work was carried out by SM. The manuscript was written through contributions of all authors. All authors have given approval to the final version of the manuscript.

\section{Acknowledgment}

The authors gratefully thank the Swiss National Science Foundation (SNF) for the grant provided to support the research on the use of nanoparticles to detect fingermarks (Ambizione grant no. PZ00P2_121907/139952). 


\section{References}

[1] Menzel R E 2001 Fingerprint detection with photoluminescent nanoparticles Advances in Fingerprint Technology, 2nd ed. Lee H C and Gaensslen R E (Boca Raton, FL: CRC Press) pp 211-40

[2] Choi M J, McDonagh A M, Maynard P and Roux C 2008 Metal-containing nanoparticles and nano-structured particles in fingermark detection Forensic Sci. Int. 179 87-97

[3] Dilag J, Kobus H J and Ellis A V 2011 Nanotechnology as a New Tool for Fingermark Detection: A Review Current Nanoscience 7 153-9

[4] Jaber N, Lesniewski A, Gabizon H, Shenawi S, Mandler D and Almog J 2012 Visualization of Latent Fingermarks by Nanotechnology: Reversed Development on Paper-A Remedy to the Variation in Sweat Composition Angew. Chem. Int. Ed. 51 12224-7

[5] Spindler X, Shimmon R, Roux C and Lennard C 2011 The effect of zinc chloride, humidity and the substrate on the reaction of 1,2-indanedione-zinc with amino acids in latent fingermark secretions Forensic Sci. Int. 212 150-7

[6] Beaudoin A 2004 New technique for revealing latent fingerprints on wet, porous surfaces: Oil Red O J. For. Ident. 54 413-20

[7] Champod C, Lennard C, Margot P and Stoilovic M. Fingerprints and other Ridge Skin Impressions (Boca Raton, FL: CRC Press, 2004)

[8] Bécue A, Moret S, Champod C and Margot P 2011 Use of stains to detect fingermarks Biotechnic \& Histochemistry $\mathbf{8 6} 140-60$

[9] Leggett R, Lee-Smith E E, Jickells S M and Russell D A 2007 "Intelligent" Fingerprinting: Simultaneous identification of drug metabolites and individuals by using antibodyfunctionalized nanoparticles Angew. Chem. Int. Ed. 46 4100-3

[10] Bécue A and Cantú A A 2012 Fingermark Detection Using Nanoparticles Lee and Gaensslen's Advances in Fingerprint Technology, 3rd ed. Ramotowski R S (Boca Raton, FL: CRC Press) pp 307-79 
[11] Bécue A, Scoundrianos A and Moret S 2012 Detection of Fingermarks by Colloidal Gold (MMD/SMD) - Beyond the pH 3 Limit Forensic Sci. Int. 219 39-49

[12] Cantú A A 2001 Silver Physical Developers for the Visualization of Latent Prints on Paper Forensic Sci. Rev. 13 29-64

[13] Theaker B J, Hudson K E and Rowell F J 2008 Doped hydrophobic silica nano- and microparticles as novel agents for developing latent fingerprints Forensic Sci. Int. 174 26-34

[14] Bécue A, Moret S, Champod C and Margot P 2009 Use of quantum dots in aqueous solution to detect blood fingermarks on non-porous surfaces Forensic Sci. Int. 191 36-41

[15] Choi M J, McDonagh A M, Maynard P J, Wuhrer R, Lennard C and Roux C 2006 Preparation and evaluation of metal nanopowders for the detection of fingermarks on nonporous surfaces J. For. Ident. $\mathbf{5 6}$ 756-68

[16] Sametband M, Shweky I, Banin U, Mandler D and Almog J 2007 Application of nanoparticles for the enhancement of latent fingerprints Chem. Commun. 1142-4

[17] Schnetz B and Margot P 2001 Technical Note: Latent fingermarks, colloidal gold and multimetal deposition (MMD) Optimisation of the method Forensic Sci. Int. 118 21-8

[18] Ramotowski R S 2001 Composition of a latent print residue Advances in Fingerprint Technology, 2nd ed. Lee H C and Gaensslen R E (Boca Raton, FL: CRC Press) pp 63-104

[19] Girod A, Ramotowski R and Weyermann C 2012 Composition of fingermark residue: A qualitative and quantitative review Forensic Sci. Int. 223 10-24

[20] Yang R, Wang Y, Xia B, Wang Y and Liu J 2011 Application of CdTe Quantum Dots to Development Fingerprints on Adhesive Surfaces Mater. Sci. Forum 694 874-80

[21] Saunders G 1989 Multimetal Deposition Technique for Latent Fingerprint Development. International Association for Identification, (ed.). 74th IAI Educational Conference. Pensacola, FL, USA

[22] Stauffer E, Bécue A, Singh K V, Thampi K R, Champod C and Margot P 2007 Single-metal deposition (SMD) as a latent fingermark enhancement technique: An alternative to multimetal deposition (MMD) Forensic Sci. Int. 168 e5-e9 
[23] Saunders G and Cantú A A 1991 Universal process for fingerprint detection Los Alamos National Laboratory Publication April

[24] Choi M J, McBean K E, Wuhrer R, et al. 2006 Investigation into the binding of gold nanoparticles to fingermarks using scanning electron microscopy J. For. Ident. 56 24-32

[25] Liu L, Gill S K, Gao Y, Hope-Weeks L J and Cheng K H 2008 Exploration of the use of novel $\mathrm{SiO}_{2}$ nanocomposites doped with fluorescent $\mathrm{Eu}^{3+} /$ sensitizer complex for latent fingerprint detection Forensic Sci. Int. 176 163-72

[26] Liu L 2011 Study on the Use of Rhodamine Doped Nanocomposite for Latent Fingerprint Detection Advanced Materials Research 295-297 813-6

[27] Wang L, Yang C and Tan W 2005 Dual-Luminophore-Doped Silica Nanoparticles for Multiplexed Signaling Nano Lett. 5 37-43

[28] Bagwe R P, Hilliard L R and Tan W 2006 Surface Modification of Silica Nanoparticles to Reduce Aggregation and Nonspecific Binding Langmuir 22 4357-62

[29] Bagwe R P, Yang C, Hilliard L R and Tan W 2004 Optimization of Dye-Doped Silica Nanoparticles Prepared Using a Reverse Microemulsion Method Langmuir 20 8336-42

[30] Samuel J, Raccurt O, Poncelet O, et al. 2010 Surface characterizations of fluorescentfunctionalized silica nanoparticles: from the macroscale to the nanoscale J. Nanopart. Res. 12 $2255-65$

[31] DeLuca T, Kaszuba M and Mattison K 2006 Optimizing Silicone Emulsion Stability Using Zeta Potential American Laboratory News 38 14-5

[32] Sam S, Touahir L, Salvador Andresa J, et al. 2010 Semiquantitative Study of the EDC/NHS Activation of Acid Terminal Groups at Modified Porous Silicon Surfaces Langmuir 26 80914

[33] Cantú A A and Johnson J L 2001 Silver physical development of latent prints Advances in Fingerprint Technology, 2nd ed. Lee H C and Gaensslen R E (Boca Raton, FL: CRC Press) pp 241-74 